\title{
Buschke-Lowenstein tumor
}

\author{
José M. Martín, ${ }^{1}$ Inmaculada Molina, ${ }^{1}$ Carlos Monteagudo, ${ }^{2}$ Nuria Marti, ${ }^{1}$ Verónica López, ${ }^{1}$ \\ Esperanza Jorda ${ }^{1}$
}

1. Department of Dermatology, Hospital Clínico Universitario Valencia, Spain

2. Department of Pathology, Hospital Clínico Universitario Valencia, Spain

Corresponding author:

José M. Martín, MD

Servicio de Dermatología

Hospital Clínico Universitario

Avenida Blasco Ibanez 17

46010. Valencia. Spain

E-mail: jmmart@eresmas.com

\section{Key words:}

condylomata acuminata, lasers, penile neoplasms, squamous cell carcinoma, verrucous carcinoma

\begin{abstract}
Background: Verrucous carcinoma of the skin and mucosa is an uncommon type of well-differentiated squamous cell carcinoma. When it is present in the genitoanal region the term used is Buschke-Lowenstein tumor. The human papillomavirus seems to be implicated in its aetiology. Treatment is controversial. Topical chemotherapy, radiotherapy, immunotherapy and radical surgery have been employed.
\end{abstract}

Main Observations: We report a rapidly progressing penile verrucous carcinoma which was treated sucessfuly with conservative surgery and $\mathrm{CO}_{2}$ laser.

Conclusion: Treatment with $\mathrm{CO}_{2}$ laser in combination with conservative surgery may be a therapeutic option in Buschke-Lowenstein tumor.

\section{Introduction}

Verrucous carcinoma of the skin and mucosa is an uncommon type of well-differentiated squamous cell carcinoma. When it is present in the genitoanal region the term used is Buschke-Lowenstein tumor. It is characterized by a slow and locally invasive growth pattern. Clinically, they present as exophytic, fungating masses, sometimes with a cauliflower-like morphology. The gross appearance is generally a bulky tumor suggesting an aggressive behavior, whereas histopathology reveals a relatively low-grade malignancy. Biologically, this tumor shows high recurrence rate and it is typified by a low incidence of metastasis. ${ }^{1-5}$

Diagnosis of verrucous carcinoma may be difficult because of the lack of cytological features of malignancy and particularly if biopsy specimen involves only the surface epithelium. Large and deep biopsies and careful sectioning and complete histologic examination are mandatory. Microscopic features are similar to those of a viral wart, but in a large biopsy or excisional specimen, it can be differentiated by its characteristic "pushing" endophytic-invasive margin, by negligible cellular atypia and a low mitotic rate.

\section{Report of a case}

A 42-year-old man requested medical attention for a progressively enlarging lesion located on his penis, that he had noticed for 4 months. Physical examination revealed a $7 \mathrm{~cm}$ exophytic tumor affecting completely the prepuce and part of the glans (Fig. 1). The patient had not history of genital warts. No locoregional lymph nodes were present upon palpation.

A diagnosis of squamous cell carcinoma, verrucous carcinoma or giant condyloma acuminatum was suspected.

Histologically, an epidermal squamous exophytic growth was found with marked papillomatosis, acanthosis, and hyperkeratosis with extensive parakeratosis. Koilocyte-like changes were focally present in superficial areas. Squamous cells showed a low grade atypia, an 


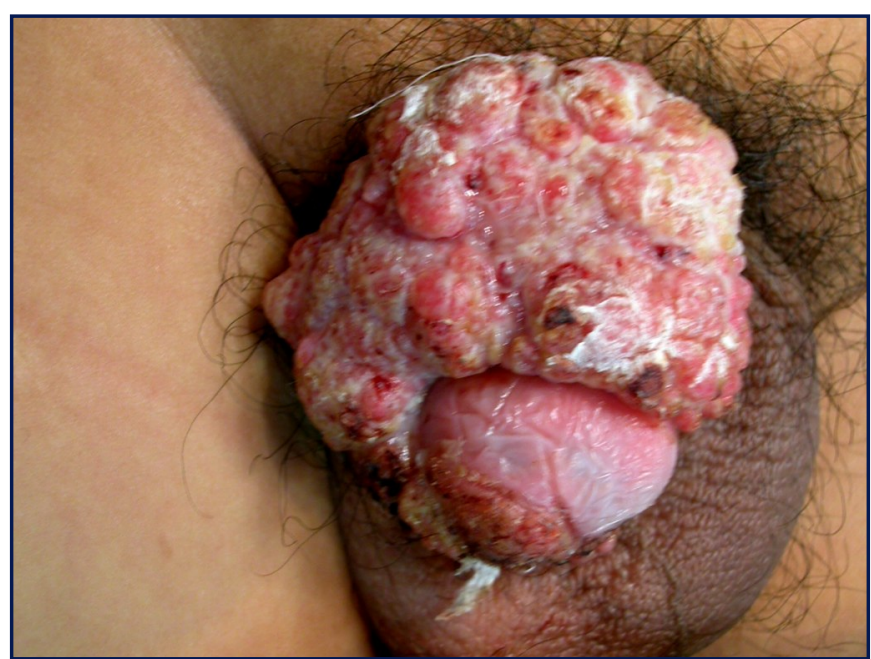

Figure 1

Exophytic tumor affecting completely the prepuce and part of the glans.

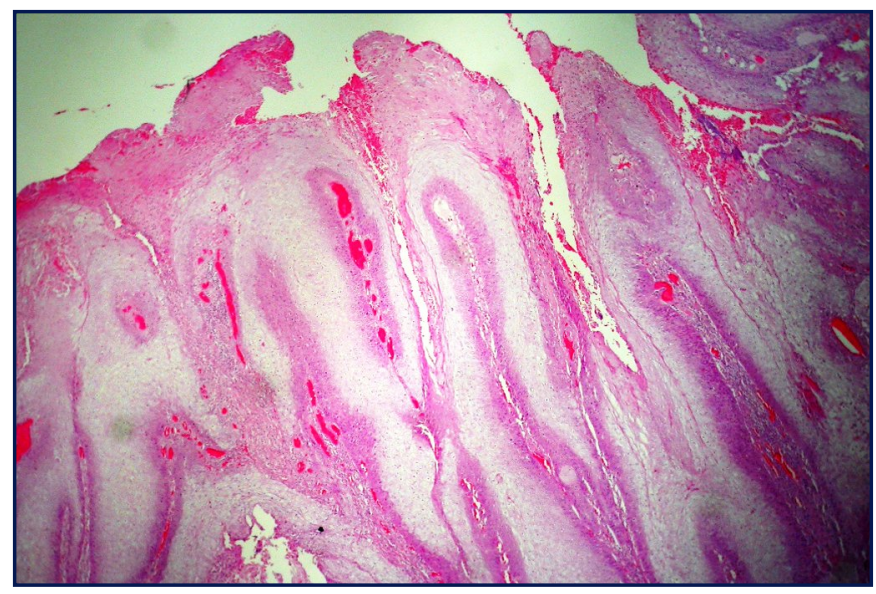

Figure 2

Exophytic squamous proliferation with marked papillomatosis and low atipia. Hematoxylin-eosin, 40x.

expansive pattern of invasion, and a moderate number of mitoses. Some tumor nests had central collections of neutrophils. These findings were consistent with a diagnosis of verrucous carcinoma (Fig. 2, Fig. 3).

The lesion was treated with conservative surgery and laser. On 3-year follow-up he did not develop neither local recurrence nor distant metastasis.

\section{Discussion}

Buschke-Lowentein tumor is classified as a verrucous carcinoma. ${ }^{1-4}$ The term of verrucous carcinoma was first introduced by Ackerman in 1948 in the oral cavity and was designated as a variant of squamous cell carcinoma with distinct features including well-differentiated, slow locally invasive growth and verrucous appearance. Although, as initially described, the oral cavity is the most common site, it has become evident that similar lesions

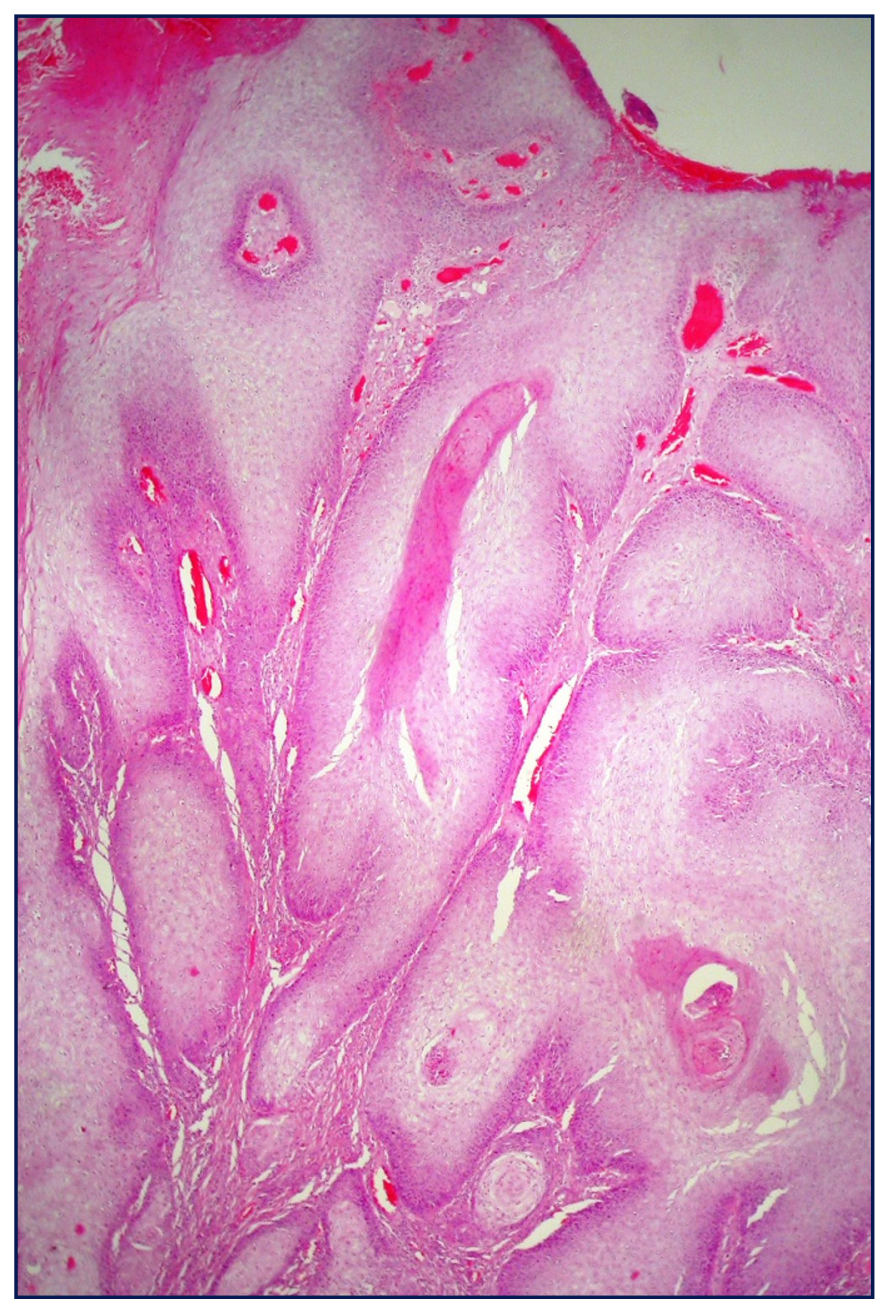

Figure 3

Tumor invasion was present at the base of the lesion. Hematoxylin-eosin, 40x.

can also be recognized in the skin, upper aerodigestive tract, and anogenital sites. ${ }^{4}$

It is a rare condition, and its pathogenesis and natural history are not well understood. Some authors have proposed that represents an intermediate state between condyloma acuminatum and squamous cell carcinoma. ${ }^{6}$ Presumably, for unknown reasons, a very small subset of long-lasting condyloma acuminatum eventually evolve into slowly invading tumors and then, if left untreated, into large papillomatous proliferations that penetrate deeply into the underlying tissue. ${ }^{7}$ A characteristic of Buschke-Lowenstein tumor is its benign-appearing histologic appearance, which resembles that of condyloma acuminatum. It may be difficult to distinguish between these 2 conditions, particularly at an early stage of the disease. ${ }^{8}$

There seems to be much confusion regarding the terminology of this rare tumor; it was variously described as giant condyloma acuminate, squamous papillomatosis, condyloma acuminata with malignant transformation, and well-differentiated squamous cell carcinoma. However, verrucous carcinoma presents as a distinct entity with exoendophytic growth pattern (in contrast to condyloma accuminata) of squamous cells showing mild atypia 
with pushing margins (in contrast to the invasive character of well-differentiated squamous carcinoma). These are reflected in slow-growing lesions, locally invasive behavior, and very infrequent metastatic spread. 8

Although several etiologic factors are implicated in the malignant transformation, the etiology of verrucous carcinoma is not known. Human papillomavirus type 6 or 11 DNA is regularly found in verrucous carcinomas, suggesting a pathogenic role in tumor development. ${ }^{9-12}$ These low-risk HPV types normally lack malignant potential, as they are found in benign condyloma acuminatum but not in anogenital cancers, which usually contain DNA of highrisk HPV, mainly types 16 or 18 . In spite of this, the role of human papillomavirus (HPV) in the etiology of verrucous carcinoma has not yet been clarified. It has to be demonstrated more specifically if HPV presence is a coincidence or a cofactor in carcinogenesis. It remains unknown which viral or host risk factors, such as increased viral gene expression or inability to mount a cytotoxic immune response, may change the oncogenic potential of HPV types 6 or 11, causing progression of benign condyloma acuminatum to the invasive giant condyloma phenotype. Moreover, it is believed that malignant transformation should also be caused by the release of free oxygen radicals by activated inflammatory cells, inducing genetic damage and neoplastic transformation. 8,13-16

Most authors recommend the radical surgical excision, allowing a complete histological examination and assessment of tumor-free resection margins. Other adjuvant treatment modalities could be of interest to avoid mutilating surgical interventions such as laser, radiotherapy, intralesional interferon alfa, or topic imiquimod.1,8,17-20 $\mathrm{A}$ regular follow-up is necessary because of the frequent recurrences and possible malignant transformation. Malignant transformation has been reported in up to $50 \%$ of cases, ${ }^{6}$ which is associated with a high recurrence rate and poor prognosis.

\section{References}

1. Levy A, Lebbe C. Buschke-Lowenstein tumor: diagnosis and treatment. Ann Urol. (Paris) 2006; 40: 175-178.

2. Steffen C. The men and the eponym. Abraham Buschke and Ludwig Lowenstein: giant condyloma (Buschke-Lowenstein). Am J Dermatopathol. 2006; 28: 526-536.

3. Lonhacre TA, Kong CS, Welton ML. Diagnostic problems in anal pathology. Adv Anat Pathol. 2008; 15: 263-278.

4. Mentes O, Akbulut M, Bagci M. Verrucous carcinoma (Buschke-Lowenstein) arising in a sacrococcygeal pilonidal sinus tract: report of a case. Verrucous carcinoma (BuschkeLowenstein) arising in a sacrococcygeal pilonidal sinus tract: report of a case. Langenbecks Arch Surg. 2008; 393: 111-114.
5. Chao MW, Gibbs P. Squamous cell carcinoma arising in a giant condyloma acuminatum (Buschke-Lowenstein tumor). Asian J Surg. 2005; 28: 238-240.

6. Creasman C, Haas CA, Fox TA, Balazs M. Malignant transformation of anorectal giant condyloma acuminatum (Buschke Lowenstein tumor). Dis Colon Rectum. 1989; 32: 481-487.

7. Björck M, Athlin L, Lundskog BA. Giant condylomata acuminate (Buschke-Löwenstein tumor of the anorectum with malignant transformation). Eur J Surg. 1995; 161: 691-694.

8. Geusau A, Heinz-Peer G, Volc-Platzer B, Stingl G, Kirnbauer $R$. Regression of deeply infiltrating giant condyloma (Buschke-Löwenstein tumor) following long-term intralesional interferon alfa therapy. Arch Dermatol. 2000; 136: 707-710.

9. Gissman L, de Villiers EM, zur Hausen H. Analysis of human genital warts (condyloma acuminata) and other genital tumors for human papillomavirus type 6 DNA. Int J Cancer. 1982; 29: 143-146.

10. Wells M, Robertson S, Lewis F. Squamous carcinoma arising in giant perianal condyloma associated with human papillomavirus types 6 and 11. Histopathology. 1988; 12: 319-323.

11. Crowther ME, Shepherd JH, Fisher C. Verrucous carcinoma of the vulva containing human papillomavirus-11. Case report. Br J Obstet Gynaecol. 1988; 95: 414-418.

12. Benchekroun A, Nouini $Y$, Zennoud M, Kermouni T, Iken A, Ghadouane M, Alami M. Verrucous carcinoma and BuschkeLowenstein tumors: apropos of 2 cases. Ann Urol. (Paris). 2002; 36: 286-289.

13. Creasman C, Haas PA, Fox TA, Balazs M. Malignant transformation of anorectal giant condyloma acuminatum (BuschkeLowenstein tumor). Dis Colon Rectum. 1989; 32: 481-487.

14. Chu QD, Vereridis MP, Libbey NP, Wanebo HJ. Giant condyloma acuminatum (Buschke-Lowenstein) tumor of the anorectal and perianal regions. Dis Colon Rectum. 1994; 37: 950-957.

15. Bertram P, Treutner KH, Rubben A, Hauptmann S, Schumpelick V. Invasive squamous cell carcinoma in giant anorectal condyloma (Buschke Lowenstein tumor). Langenbecks Arch Cir. 1995; 380: 115-118.

16. Gur E, Neligan PC, Shafir R, Reznick R, Cohen M, Shpitzer $\mathrm{T}$. Squamous cell carcinoma in perineal inflammatory disease. Ann Plast Surg. 1997; 38: 653-657.

17. Frega A, Stentella P, Tinari A, Vecchione A, Marchionni M. Giant condyloma acuminatum or buschke-Lowenstein tumor: review of the literature and report of three cases treated by $\mathrm{CO}_{2}$ laser surgery. A long-term follow-up. Anticancer Res. 2002; 22: 1201-1204.

18. Heinzerling LM, Kempf W, Kamarashev J, Hafner J, Nestle FO. Treatment of verrucous carcinoma with imiquimod and $\mathrm{CO}_{2}$ laser ablation. Dermatology. 2003; 207: 119-122.

19. Gholam P, Enk A, Hartschuh W. Successful Surgical Management of Giant Condyloma Acuminatum (Buschke-Löwenstein Tumor) in the Genitoanal Region: A Case Report and Evaluation of Current Therapies. Dermatology. 2008. Oct 21. Epub ahead of print

20. Schwartz RA. Verrucous carcinoma of the skin and the mucosa. J Am Acad Dermatol. 1995; 32: 1-21. 